https://helda.helsinki.fi

\title{
The expression and prognostic relevance of programmed cell death protein 1 in tongue squamous cell carcinoma
}

\section{Tervo, Sanni}

2020-12

Tervo , S , Seppala , M , Rautiainen, M , Huhtala , H , Salo , T , Al-Samadi , A , Kuopio , T, Ahtiainen, M , Tommola , S , Paavonen , T \& Toppila-Salmi , S 2020 , ' The expression and prognostic relevance of programmed cell death protein 1 in tongue squamous cell carcinoma ' , APMIS : Acta pathologica, microbiologica et immunologica Scandinavica, vol. 128 , no. 12 , pp. 626-636 . https://doi.org/10.1111/apm.13084

http://hdl.handle.net/10138/335432

https://doi.org/10.1111/apm.13084

acceptedVersion

Downloaded from Helda, University of Helsinki institutional repository.

This is an electronic reprint of the original article.

This reprint may differ from the original in pagination and typographic detail.

Please cite the original version. 


\section{The expression and prognostic relevance of programmed cell death protein 1 in tongue squamous cell carcinoma}

Sanni Tervo $o^{a, b, c}$ MD, Miia Seppäläa MD, Markus Rautiainen ${ }^{d}$ MD, PhD, Heini Huhtala ${ }^{e}$ MSc, Tuula Salo ${ }^{f}$ PD, Ahmed Al-Samadif DDS, PhD, Teijo Kuopio, ${ }^{\mathrm{g}, \mathrm{h}} \mathrm{MD}$, PhD, Maarit Ahtiainen ${ }^{\mathrm{i}} \mathrm{PhD}$, Satu Tommola ${ }^{\mathrm{c}}$ MD, Timo Paavonen $^{\mathrm{b}, \mathrm{c} \dagger} \mathrm{MD}, \mathrm{PhD}$, Sanna Toppila-Salmi ${ }^{\mathrm{a}, \mathrm{j} \dagger} \mathrm{MD}, \mathrm{PhD}$

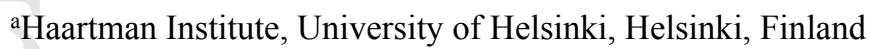

bepartment of Pathology, Faculty of Medicine and Health Technology, Tampere University, Tampere, Finland

${ }^{\mathrm{c}}$ Fimlab laboratories Ltd., Tampere, Finland

dDepartment of Otorhinolaryngology, Faculty of Medicine and Health Technology, Tampere University, Tampere,

Finland

eFaculty of Social Sciences, Tampere University, Tampere, Finland

fDepartment of Oral and maxillofacial diseases, Clincium, University of Helsinki, Helsinki, Finland

gDepartment of Pathology, Central Finland Central Hospital, Jyväskylä, Finland

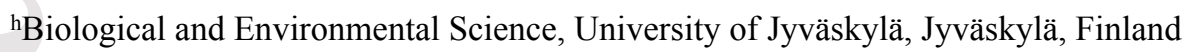

iDepartment of Education and research, Central Finland Central Hospital, Jyväskylä, Finland

jSkin and Allergy Hospital, Helsinki University Hospital and University of Helsinki, Helsinki, Finland

†Shared last author

Corresponding author Sanni Tervo, Haartman Institute, PO BOX 21 (Haartmaninkatu 3), 00014 University of

Helsinki, Helsinki, Finland. E-mail: sanni.tervo@fimnet.fi Tel: +358 442582855

Running title PD-1 expression and its prognostic value in TSCC.

This article has been accepted for publication and undergone full peer review but has not been through the copyediting, typesetting, pagination and proofreading process, which may lead to differences between this version and the Version of Record. Please cite this article as doi: $\underline{\text { 10.1111/APM.13084 }}$

This article is protected by copyright. All rights reserved 


\section{The expression and prognostic relevance of programmed cell death protein 1 in tongue squamous cell carcinoma}

\section{Summary}

Background Programmed cell death protein 1 (PD-1) is an immune checkpoint receptor which plays an important role in a patient's immune responses to microbial and cancer antigens. It is expressed in tumor infiltrating lymphocytes (TILs) with many different malignancies. The aim of the study was to evaluate PD-1 expression and its prognostic value in tongue cancer. Methods The data of tongue squamous cell carcinoma (TSCC) patients $(\mathrm{N}=81)$ treated in Tampere University Hospital between 1999-2013 was used. Control data consisted of patients with nonmalignant tongue mucous membrane lesions $(\mathrm{N}=48)$. The formalin-fixed paraffin-embedded samples were stained immunohistochemically and scanned via digital microscope. The staining of

PD-1 was examined semi-quantitatively. Results The density and intensity of PD-1+ cells were significantly higher in TSCC than in control samples. The expression of PD-1 correlated with better survival. Conclusions The expression of PD-1 could be a potential prognostic marker in TSCC. Further research using larger sample size is needed.

Key words Programmed cell death protein 1 (PD-1), tongue squamous cell carcinoma, prognosis, immunohistochemistry, molecular marker. Corresponding author Sanni Tervo, Haartman Institute, PO BOX 21 (Haartmaninkatu 3), 00014 University of Helsinki, Helsinki, Finland. E-mail: sanni.tervo@fimnet.fi 


\section{Introduction}

Tongue squamous cell carcinoma (TSCC) is one of the most common subtypes of oral cancer.

Oral and pharyngeal cancer together are the sixth most common cancer worldwide (1). While the incidence and mortality of oral cancer has remained stable or slowly decreased over last decades

in United States and Western Europe, the incidence of oropharyngeal squamous cell carsinoma has explosively increased in the same area at least partly due to increased incidence of human papilloma virus (HPV) infection (2-6). Mortality for cancers of the tongue, oral cavity and oropharynx differs considerably by region; for most countries, five-year overall survival rates are around $50 \%$ depending mainly on tumor location, size and the existence of metastasis (1,7-9).

Due to aggressive behavior of TSCC patients have worse prognosis when compared with similar lesions of the oropharynx, larynx, hypopharynx, and other oral cavity sites (10). In clinical use the presence of nodal metastasis in the neck is the most important prognostic factor in TSCC. Because of the high risk of occult micrometastasis, the use of neck dissection in the surgical management of early stage TSCC has been the prevalent recommendation over the last years (1113). The classification of TNM (tumor size, node and metastasis) has still an important role for a clinicist when planning treatments. Tumor grade is also still widely used, but it seems to have only little value in prognostication in most studies. Some other proposed prognostic risk factors in TSCC are high risk HPV infection in base of tongue carcinoma, cancer microenvironment-related markers, tumor extranodal growth, apoptosis, tumor budding and white adipose tissue inflammation (14-20). In addition, numerous molecular markers have been examined, but none of those have been adopted to routine clinical use for TSCC $(20,21)$. 
Because of the high rate of occult metastasis and therefore extremely high invasive treatments, there is need for prognostic factors suitable for clinical use. Programmed cell death protein 1 (PD1) function as an immune checkpoint receptor. It is a part of a patient's own immune responses for infection or cancer and thus a favorable potentional target for immunotherapeutics in cancer treatment. At the time of inflammatory response, activation of T cells leads to increased expression of PD-1, which limits the activity of T lymphocytes in peripheral tissues and thus inhibits immune responses (22). The expression of PD-1has been found in tumor infiltrating lymphocytes (TILs) in several different malignancies such as thyroid cancer, B-cell lymphoma, hepatocellular carcinoma, breast cancer, gastric cancer, non-small-cell lung cancer, head and neck cancer, and it is widely proposed to be a potentional prognostic biomarker factor (23-33). It has been found that anti-PD-1 monoclonal antibody pembrolizumab had a favorable safety profile and a clinically meaningful prolongation of overall survival in patients with recurrent or metastatic head and neck squamous cell carcinoma in a phase III study (34).

There is limited knowledge of PD-1 expression in TSCC. The aim of the study was to evaluate the PD-1 expression in non-malignant tongue lesions and in the TSCC tissue and its prognostic value among TSCC patients. The hypothesis was that PD-1 associates with TSCC patient's prognosis.

\section{Materials and methods}

\section{Clinical samples}

The ethical committees of Hospital District of Pirkanmaa (no. R07039) and The National Supervisory Authority for Welfare and Health approved the study design and gave permissions. 
The data collection was performed through noninvasive procedures with the routine treatment. Samples couldn't be identified by the researchers, since all identifying information was removed.

The formalin-fixed paraffin-embedded samples were collected retrospectively from the archives of the Tampere University Hospital, Tampere, Finland. The samples were taken from 87 patients who had been treated for TSCC between 1999-2013. Six patients were excluded from the final analysis for the following reasons: For three patients ( 8 samples) the histopathological diagnosis turned out to be other than TSCC (one tonsilla carcinoma, one hypopharynx carcinoma and one larynx carcinoma); two carcinoma samples had not been scanned; one carcinoma sample did not contain enough tumor material for the microscopical staining evaluation. Thus, the final number of samples was 81 patients; 63 of stained TSCC samples were from surgical resections and 27 samples were diagnostical biopsies. Both a surgical resection preparate sample and a diagnostical biopsy were available from nine patients out of all 81 patients. In those cases, only the surgical preparate sample was included. Lymph node samples were available from 19 patients. Of these, 18 patients had at least one metastatic lymph node and only one had a lymph node metastasis negative disease. There were four metastatic lymph node samples, that had no or small sized metastatic areas in the selected sample and were thus excluded from the analysis.

Tongue tissue samples were also collected from 51 patients treated for non-malignant lesions between 1999-2013. Because of lack of a representative sample, three samples were excluded, thus the final number of samples of the control group was 48 patients. Tongue samples' histopathological diagnosis of the control group were 31 hyperplasia, eight hyperkeratosis, one parakeratosis, one hyperkeratosis-parakeratosis, one chronic inflammation and six normal tissue or no diagnostic abnormality. There were thirty-seven biopsies and 11 patients, who had the 
epithelial change resected in full. No other inclusion criteria were set. Possible chemoradiotherapy was prescribed case by case based on international treatment recommendations.

\section{Tissue handling and immunohistochemistry}

The staining of PD-1 was performed on 171 samples. Before performing immunohistochemistry, the pathologist (TP) reviewed all samples by a light microscope and selected the samples with the most representative pathological signs of cancer or benign tissue with no or very small amount of necrosis. There were 27 samples excluded from the final analysis due to the reasons mentioned above. Formalin fixed and paraffin embedded tissue samples were cut into sections and placed on microscope slides. Staining for PD-1 was conducted with anti-PDCD1 (SP269, 1:50; Spring Bioscience) using a BOND-III IHC stainer (Leica Biosystems). Antigen retrieval was performed using Tris/EDTA (BOND Epitope Retrieval Solution 2, pH9; Leica Biosystems) for 20 minutes. Endogenous peroxidase was blocked with $3 \% \mathrm{H} 2 \mathrm{O} 2$ for 5 minutes. Post primary rabbit anti-mouse linker and anti-rabbit horseradish-peroxidase labelled polymer was used for 8 minutes.

Diaminobenzidine for 10 minutes was used for signal visualization, and counterstaining with hematoxylin for 10 minutes was done before mounting.

\section{Microscopic evaluation}

Before evaluation, immunohistochemistry stained tissue slides were scanned via digital microscope with a NanoZoomer-XR (Hamamatsu Photonics) at 40X magnification. The preliminary intensity of PD-1 positively stained cells in tongue squamous cell cancer, control tissue and lymph nodes were examined with NDP view 2 Viewing software (Hamamatsu

Photonics K.K., Japan) by three observers (ST, SS and TP) without knowledge of clinical status 
and outcome data. Cases of disagreement were discussed, and a consensus was determined for further analysis.

The representative tumor areas and invasive front were marked by using Freehand line annotation. Ten fields (a' $0,2 \mathrm{~mm} 2$, Circle annotation) in tumor resection specimens were picked. These were, five from intratumoral and five from invasive front area with 1,25x magnification. In this study invasive front was defined as the outermost cell layers of the tumor. In biopsies, lymph node metastasis samples and control specimens we picked as a whole five fields from intraepithelial area. All the areas were picked without the actual knowledge of PD-1 cell staining density.

All positively (brown colored) stained cells from these areas were counted manually by one observer (ST) with 40x magnification and each cell was individually categorized into one of two types based on staining intensity (weak staining or intermediate to strong staining intensity, see Figure 1.). The cell density (positively stained cells $/ \mathrm{mm} 2$ ) was calculated by dividing the sum of positively stained cells from all fields by the sum of fields' areas (for intratumoral PD-1density ${ }_{\text {it }}$ and for invasive front PD-1density ${ }_{\text {if }}$ ) and it was counted separately for both two intensity groups.

The density score of PD-1 staining was determined as $1=$ less than $50,2=50-99,3=100-149$, 4= 150-199, 5=200-299, $6=300$ or more cells $/ \mathrm{mm} 2$. The intensity score of PD- 1 staining was determined as $1=$ moderate or strongly stained cells proportion from all stained cells less than $5 \%$, $2=$ moderate or strongly stained cells proportion from all stained cells 5 to $49 \%, 3=$ moderate or strongly stained cells proportion from all stained 50 to $59 \%, 4=$ moderate or strongly stained proportion from all stained 60 to $69 \%, 5=$ moderate or strongly stained cells proportion from all 
stained 70 to $79 \%, 6=$ moderate or strongly stained proportion from all stained at least $80 \%$. The cut-off points were chosen to result in approximately equal sized groups.

The survival analysis was performed by using PD-1 staining determined low or high (PD-1 ${ }^{\text {low }}$, PD$1^{\text {high}) ~ b a s e d ~ o n ~ c l a s s i f i c a t i o n, ~ w h i c h ~ t a k e s ~ i n t o ~ a c c o u n t ~ t h e ~ p r o b l e m ~ o f ~ t o t a l ~ s c o r e ~ w i t h ~ h i g h ~ v a l u e s ~}$ of intensity score combined with low values of density score (see Supplement Figure 1).

\section{Data analysis}

Statistical analyses were carried out using SPSS Statistics version 24 (Property of IBM Corp) 64bit edition. Descriptive statistics for patients and tumor characteristics were assessed in TSCC and in benign tongue. Fisher's exact test (2-tailed) and Mann-Whitney U were used in comparisons. Associations were assessed by survival models with Log-rank test, Fisher's exact test (dichotomous), Kruskal-Wallis and Mann Whitney U tests (continuous). Univariate and multivariable Cox's proportional hazard models for survival were constructed with the following six predictor variables: gender, age, smoking, metastasis, tumor size, and tumor depth. The statistically significant variables were entered to the multivariable Cox's proportional hazard model. Two-tailed $P$-values of $<0.05$ were considered statistically significant in all models.

\section{Results}

\section{Patients and tumor characteristics}

The demographic data, collected from patient records, are shown in Table 1. The average age in the control group was 58 years (range 28-84) and in the tongue cancer group it was 60 years 
(range 17-94). There were 34 (42\%) of TSCC patients aged between 50 and 65 years, seven $(8.6 \%)$ of the patients were under 35 . Numbers of previous or current smoking and heavy alcohol drinking were higher in TSCC group. No difference was found between other tested parameters. Follow-up period (in months) of patients at the end of the study was 66.8 (median) and 78.4 (mean) (range $=1-221)$.

A tumor size more than $4 \mathrm{~cm}$ (based on clinicist set TNM class) was found in $29(35.8 \%)$ of tongue cancer patients, $24(29.6 \%)$ had early stage (T1-T2N0M0) disease. Of those who had metastatic disease, $38(84.4 \%)$ had pathological signs of metastatic tumor growth (e.g. pN+), 13 (28.9\%) had extranodal growth in cervical LNs and three (6.7\%) had distant metastasis. The median (min-max, mean) number of $\mathrm{pN}+$ cervical LNs was $2(1-8,2.21)$ and median (min-max, mean) number of cervical LNs with extranodal invasion was $0(0-5,0.47)$. Out of all tongue cancer patients $66(81.5 \%)$ patients underwent operation. Of the operated patients $58(87.9 \%)$ underwent additional lymph node management.

\section{The expression of PD-1 in non-malignant mucous membrane lesions and TSCC}

The expression of PD-1 was detected in the cytoplasm of tumor infiltrating lymphoid cells and in non-malignant mucous membrane infiltrating by immune cells in a smaller amount (Figue 1). No PD-1 expression in epithelial cells' cytoplasm was found, which is in line with previous studies. The differentation into lymphoid cells and epithelial cells was based on well known special features of those cell groups. The density of intratumoral PD- $1^{+}$cells was significantly higher in tongue cancer than the positively stained cell density in benign tongue $(p<0.001$, Mann-Whitney U, Figure 2A). Also the intratumoral staining intensity (per cents), was statistically significantly 
higher in TSCC group than in control group ( $p<0.001$, Mann-Whitney U, Figure 2B). The evaluated parameters did not differ when using the whole tumor PD-1 density or intensity.

\section{Association of tumor PD-1 expression in TSCC sub-groups}

The intratumoral PD-1 density, staining intensity (moderate or strongly stained cells proportion from all stained cells) or total score (eg. density score $\mathrm{x}$ intensity score) did not differ between TSCC groups classified by $\mathrm{T}$ class (T1-T4). The results remained similar when observing the invasive front area. Differencies were not found when using the whole tumor area. The evaluated parameteres did not differ between tumor groups classified by grades I-III.

There was no correlation with intratumoral, invasive front or whole tumor PD-1 expression density (PD-1+/mm2), intensity (per cents) or total score (eg. density score $\mathrm{x}$ intensity score) and with the number of cervical LNs with metastatic tumor growth or the number of cervical LNs with extranodal invasion ( $p>0.05$ by Spearman rank correlation test).

\section{Association of nodal PD-1 expression in TSCC sub-groups}

We evaluated PD-1 expression from the available cervical LN+ samples $(n=14)$ of the TSCC patients. The density or intensity of the PD-1+ cells did not differ significantly between T1-T4 TSCC groups (data not shown). No correlation was found between nodal intratumoral PD-1 density and tumor invasion depth or size $(\mathrm{mm})(p>0.14)$. Nodal intratumoral PD-1 total score had significant negative correlation with high tumor invasion depth and size $(\mathrm{mm})(p=0.043, \mathrm{p}=0.035$ $\mathrm{r}=-0.548,-0.564)$. In addition, PD-1 intensity had negative correlation with high invasion depth $(\mathrm{p}=0.014 \mathrm{r}=-0.637)$, but not with tumor size $(\mathrm{p}=0.198)$. 


\section{The prognostic relevance of PD-1 expression in TSCC}

When observing all TSCC patients' intratumoral PD-1 staining, PD-1 1ow associated with poor disease-specific and overall survival (Figure 3A). Similar finding was discovered in the invasive front (Figure 3B). When observing TSCC sub-groups with greater tumor size ( $\geq 40 \mathrm{~mm})$, with cervical LN metastasis, intratumoral PD-1 ${ }^{\text {low }}$ associated with poor disease-specific and overall survival as did also invasive front PD-1 1ow (Figure 3C-F). When observing the TSCC sub-groups with greater tumor invasion depth ( $\geq 4 \mathrm{~mm})$, the invasive front PD-1 ${ }^{\text {low }}$ associated with poor disease-specific and overall survival (Figure $3 \mathrm{G}$ and $\mathrm{H}$ ), whereas the intratumoral PD-1 staining did not ( $p>0.05$, by Log-rank test). When observing resection margin involvement $(<3 \mathrm{~mm})$, the invasive front PD-1 ${ }^{\text {low }}$ associated with poor overall survival (Figure 3I), but not with diseasespecific survival Figure 3J). Intratumoral PD-1 staining did not associate with resection margin involvement $(p>0.05)$. When observing all TSCC patients with available cervical LN samples, nodal PD-1 staining did not affect survival $(p>0.05)$.

The cut-off value for PD-1 staining density was based on AUROC analysis, (see Supplement Figure 2), which showed moderate specificity and sensitivity. The results remained similar (Supplement Figure 3).

\section{Cox regression analysis}

Disease-specific survival was also tested for the following 11 factors by Cox regression: age, gender, smoking, previous chemoradiotherapy, tumor size, tumor depth, resection margin, cervical LN metastasis, the intratumoral PD-1 staining, the invasive front PD-1 staining and nodal PD-1 
staining. In the unadjusted model, only the three following factors associated with tongue cancer death: greater tumor size $(p=0.014, \mathrm{HR}=2.327, \mathrm{CI}=1.19-4.57)$, intratumoral $\mathrm{PD}-1^{\text {low }}(p=0.047$, $\mathrm{HR}=1.993, \mathrm{CI}=1.01-3.93)$ and invasive front $\mathrm{PD}-1^{\text {low }}(p=0.010, \mathrm{HR}=2.986, \mathrm{CI}=1.30-6.88)$. When analyzing these three factors in the multivariable model, there was an insignificant trend that invasive front PD-1 ${ }^{\text {low }}$ associated with tongue cancer death (Table 3 ).

\section{Discussion}

We demonstrated that low PD-1 expression associated with poor survival in the patients with severe TSCC status, characterized by high tumor size, or the presence of cervical LN metastasis. Moreover, in the sub-groups of high tumor invasion depth, low PD-1 expression in the invasive front associated with poor prognosis. In adjusted regression survival models of TSCC patients, there was a trend that the intratumoral PD- ${ }^{\text {low }}$ was associating with tongue cancer death. In large B-cell lymphoma, colorectal cancer and HPV-associated head and neck cancer high density PD-1 ${ }^{+}$ TILs associate with favorable survival which is in line with our findings $(28,35,36)$. Badoual et al showed that HPV-positive head and neck tumors were heavily infiltrated by PD- $1^{+}$cells and PD$1^{+}$lymphocyte rates were significantly higher in HPV-positive than in HPV-negative head and neck cancers. They found that high levels of PD- $1^{+}$cells correlated with better survival compared with low levels of infiltration by these cells in primary HPV-positive head and neck cancers.

Based on Sieviläinen et al systematic review, PD-1 was studied four times in oral cancer. Ahn and Straub et al studied an association with OSCC patient survival. Both concluded that PD-1 has no value for oral cancer prognostication $(37,38)$.These different results might be explained by differences in cancer type, microscopical PD-1+ evaluation protocol or statistical analyses. Previous studies' immunohistochemical expression of PD-1 in TILs was assessed by counting the 
percentage of PD-1+ TILs, which does not consider the PD- $1+$ staining intensity $(37,38)$. The positivity of PD-1 was studied as a continuous variable in Cox regression analysis instead of as a categorical variable (37).

Expression of PD-1 has been found in lymphoid cells within tissues and tumors. The role of PD-1 is to function as immune checkpoint inhibitory receptor. When engaged by one of its ligands (PDL1 or PD-L2) it limits the action of T lymphocytes in tissues at the time of an inflammatory process or cancer by inhibating kinases that are involved in $\mathrm{T}$ cell activation. The expression of PD-1 is increased when T lymphocytes become activated. It is highly expressed on regulatory $\mathrm{T}$ cells and it may enhance regulatory $\mathrm{T}$ cells proliferation and thus suppress immune responses in tumors. In addition chronic antigen exposure can lead to high levels of PD-1 expression, which induces the exhaustion of T lymphocytes (22).

In prostate cancer, anaplastic thyroid cancer, gastric cancer, nasopharyngeal carcinoma and renal cell carcinoma high density PD-1 ${ }^{+}$TILs associate with poor prognosis, which makes sense with PD-1 function as immune system inhibitory molecule (39-43). Hsu et al showed that the prognostic value of PD-1 differed between $\mathrm{CD}^{+}$and $\mathrm{CD} 8^{+} \mathrm{T}$ cells (42). $\mathrm{CD} 8^{+} \mathrm{T}$ cells are associated with worse prognosis in renal cell carcinoma (44). Thus further studies with an increased patient sample are needed to evaluate the prognostic potential of PD-1 in TSCC.

Stronger PD-1 expression was detected in TSCC than in benign tongue tissue. In agreement with our study Sieviläinen et al's all four studies reported that PD-1 is expressed on the TILs and not on the cancer cells (45). The majority of lymphocytes were close to blood vessels which could reflect their presence in tongue tissue based on extravasation. Limited knowledge exists on benign tongue 
tumors and PD-1. We did not find any difference between the intratumoral or invasive front PD-1 expression and TSCC groups classified by T class or by grade. No correlation was found with intratumoral or invasive front PD-1 expression and with the number of cervical LNs with metastatic tumor growth or the number of cervical LNs with extranodal invasion. Ahn et al found PD-1 levels increased in older patients, while high T stage (T3- T4), N stage (N1-N2) and perineural invasion correlated with fewer PD-1+ TILs (37). Straub et al did not find any correlation between PD-1 expression and the presence of nodal metastases, age, gender, grading, tumor size, or HPV-positivity (38). We found nodal intratumoral PD-1 total score had negative correlation with high tumor invasion depth and size, also PD-1 intensity correlated negatively with high invasion depth, but not with tumor size. Interestingly, nodal PD-1 expression did not show any association with prognosis in survival analyses.

The main limitations of the study were small number of cases, heterogenous tumor sites due to including both base of the tongue and oral tongue cancers, the lack of knowledge of HPV status and characterization of TIL type. In addition some further limitations were identified, such as lack of mRNA expression data.

As a conclusion PD-1 was overexpressed in TSCC TILs when compared with benign tongue tissue infiltrating immune cells. Low PD-1 positivity correlated with worse overall and disease specific survival. Based on this, PD-1 expression could be a potential prognostic marker in TSCC. Further research with increased sample size and the knowledge of HPV status is needed to evaluate whether PD-1 could be used to determine a patient's prognosis. The aim of future studies could be to determine if it is possible to predict anti-PD-1 drug response with PD-1 expression. 


\section{Acknowledgement}

The study was supported in part by research grants from the Competitive State Research

Financing of the Expert Responsibility area of Tampere University Hospital, the Helsinki University Central Hospital Research Fund, Tampere Tuberculosis association, the Finnish

Association of Otorhinolaryngology and Head and Neck Surgery, Jane and Aatos Erkko

Foundation, Paulo Foundation, Yrjö Jahnsson Foundation, Foundation of the Finnish Anti-

Tuberculosis Association and Väinö and Laina Kivi Foundation. The authors report no conflicts of interest.

\section{References}

(1) Warnakulasuriya S. Global epidemiology of oral and oropharyngeal cancer. Oral Oncol 2009;45(4-5):309-316.

(2) Brown LM, Check DP, Devesa SS. Oropharyngeal cancer incidence trends: diminishing racial disparities. Cancer Causes \& Control 2011 May;22(5):753-763.

(3) Bonifazi M, Malvezzi M, Bertuccio P, Edefonti V, Garavello W, Levi F, et al. Age-period-cohort analysis of oral cancer mortality in Europe: the end of an epidemic? Oral Oncol 2011 May;47(5):400-407.

(4) Chaturvedi AK, Engels EA, Pfeiffer RM, Hernandez BY, Xiao W, Kim E, et al. Human papillomavirus and rising oropharyngeal cancer incidence in the United States. J Clin Oncol 2011 November 10;29(32):4294-4301.

(5) Colevas AD. Population-based evaluation of incidence trends in oropharyngeal cancer focusing on socioeconomic status, sex, and race/ethnicity. Head Neck 2014 January 01;36(1):34-42.

(6) Garnaes E, Kiss K, Andersen L, Therkildsen MH, Franzmann MB, Filtenborg-Barnkob B, et al. Increasing incidence of base of tongue cancers from 2000 to 2010 due to HPV: the largest demographic study of 210 Danish patients. Br J Cancer 2015 Jun 30;113(1):131-134.

(7) Lambert R, Sauvaget C, de Camargo Cancela M, Sankaranarayanan R. Epidemiology of cancer from the oral cavity and oropharynx. Eur J Gastroenterol Hepatol 2011 Aug;23(8):633-641.

(8) Sant M, Allemani C, Santaquilani M, Knijn A, Marchesi F, Capocaccia R, et al. EUROCARE-4. Survival of cancer patients diagnosed in 1995-1999. Results and commentary. Eur J Cancer 2009 Apr;45(6):931-991.

(9) Howlader N, Ries LAG, Mariotto AB, Reichman ME, Ruhl J, Cronin KA. Improved estimates of cancer-specific survival rates from population-based data. J Natl Cancer Inst 2010 Oct 20;102(20):1584-1598.

This article is protected by copyright. All rights reserved 
(10) Rusthoven K, Ballonoff A, Raben D, Chen C. Poor prognosis in patients with stage I and II oral tongue squamous cell carcinoma. Cancer 2008 Jan 15;112(2):345-351.

(11) Huang S, Kang C, Lin C, Fan K, Yen T, Wang H, et al. Neck treatment of patients with early stage oral tongue cancer: comparison between observation, supraomohyoid dissection, and extended dissection. Cancer 2008 Mar 01;112(5):1066-1075.

(12) D'Cruz AK, Siddachari RC, Walvekar RR, Pantvaidya GH, Chaukar DA, Deshpande MS, et al. Elective neck dissection for the management of the N0 neck in early cancer of the oral tongue: need for a randomized controlled trial. Head Neck 2009 May;31(5):618-624.

(13) Haddadin KJ, Soutar DS, Oliver RJ, Webster MH, Robertson AG, MacDonald DG. Improved survival for patients with clinically T1/T2, N0 tongue tumors undergoing a prophylactic neck dissection. Head Neck 1999 Sep;21(6):517-525.

(14) Almangush A, Bello IO, Keski-Säntti H, Mäkinen LK, Kauppila JH, Pukkila M, et al. Depth of invasion, tumor budding, and worst pattern of invasion: prognostic indicators in early-stage oral tongue cancer. Head Neck 2014 June 01;36(6):811-818.

(15) Iyengar NM, Ghossein RA, Morris LG, Zhou XK, Kochhar A, Morris PG, et al. White adipose tissue inflammation and cancer-specific survival in patients with squamous cell carcinoma of the oral tongue. Cancer 2016;122(24):3794-3802.

(16) Tai SK, Li WY, Yang MH, Chu PY, Wang YF. Perineural invasion in T1 oral squamous cell carcinoma indicates the need for aggressive elective neck dissection. Am J Surg Pathol 2013 August 01;37(8):1164-1172.

(17) Seppälä M, Pohjola K, Laranne J, Rautiainen M, Huhtala H, Renkonen R, et al. High relative density of lymphatic vessels predicts poor survival in tongue squamous cell carcinoma. Eur Arch Otorhinolaryngol 2016 December 01;273(12):4515-4524.

(18) Dahlgren L, Dahlstrand HM, Lindquist D, Hogmo A, Bjornestal L, Lindholm J, et al. Human papillomavirus is more common in base of tongue than in mobile tongue cancer and is a favorable prognostic factor in base of tongue cancer patients. Int J Cancer 2004 December 20;112(6):1015-1019.

(19) Bello IO, Soini Y, Salo T. Prognostic evaluation of oral tongue cancer: means, markers and perspectives (II). Oral Oncol 2010 September 01;46(9):636-643.

(20) Bello IO, Soini Y, Salo T. Prognostic evaluation of oral tongue cancer: means, markers and perspectives (I). Oral Oncol 2010 Sep;46(9):630-635.

(21) Almangush A, Heikkinen I, Mäkitie AA, Coletta RD, Läärä E, Leivo I, et al. Prognostic biomarkers for oral tongue squamous cell carcinoma: a systematic review and meta-analysis. Br J Cancer 2017 Sep 05;117(6):856-866.

(22) Pardoll DM. The blockade of immune checkpoints in cancer immunotherapy. Nature Reviews.Cancer 2012;12(4):252-264.

(23) Bastman JJ, Serracino HS, Zhu Y, Koenig MR, Mateescu V, Sams SB, et al. Tumor-Infiltrating T Cells and the PD-1 Checkpoint Pathway in Advanced Differentiated and Anaplastic Thyroid Cancer. Journal of Clinical Endocrinology \& Metabolism 2016 Jul;101(7):2863-2873.

(24) Cetinozman F, Koens L, Jansen PM, Willemze R. Programmed death-1 expression in cutaneous B-cell lymphoma. J Cutan Pathol 2014 Jan;41(1):14-21. 
(25) Chang H, Jung W, Kim A, Kim HK, Kim WB, Kim JH, et al. Expression and prognostic significance of programmed death protein 1 and programmed death ligand-1, and cytotoxic T lymphocyte-associated molecule-4 in hepatocellular carcinoma. APMIS 2017 Aug;125(8):690-698.

(26) Duchnowska R, Peksa R, Radecka B, Mandat T, Trojanowski T, Jarosz B, et al. Immune response in breast cancer brain metastases and their microenvironment: the role of the PD-1/PD-L axis. Breast Cancer Research 2016 Apr 27;18(1):43.

(27) Eto S, Yoshikawa K, Nishi M, Higashijima J, Tokunaga T, Nakao T, et al. Programmed cell death protein 1 expression is an independent prognostic factor in gastric cancer after curative resection. Gastric Cancer 2016 Apr;19(2):466-471.

(28) Fang X, Xiu B, Yang Z, Qiu W, Zhang L, Zhang S, et al. The expression and clinical relevance of PD-1, PD-L1, and TP63 in patients with diffuse large B-cell lymphoma. Medicine 2017 Apr;96(15):e6398.

(29) Hsu P, Yang T, Kao J, Cheng K, Lee Y, Wang Y, et al. Increased PD-1 and decreased CD28 expression in chronic hepatitis B patients with advanced hepatocellular carcinoma. Liver International 2010 Oct;30(9):1379-1386.

(30) Koh YW, Jeon YK, Yoon DH, Suh C, Huh J. Programmed death 1 expression in the peritumoral microenvironment is associated with a poorer prognosis in classical Hodgkin lymphoma. Tumour Biology 2016 Jun;37(6):7507-7514.

(31) Lafuente-Sanchis A, Zuniga A, Estors M, Martinez-Hernandez NJ, Cremades A, Cuenca M, et al. Association of PD-1, PD-L1, and CTLA-4 Gene Expression and Clinicopathologic Characteristics in Patients With Non-Small-Cell Lung Cancer. Clinical Lung Cancer 2017 Mar;18(2):e109-e116.

(32) Gatalica Z, Snyder C, Maney T, Ghazalpour A, Holterman DA, Xiao N, et al. Programmed cell death 1 (PD-1) and its ligand (PD-L1) in common cancers and their correlation with molecular cancer type. Cancer Epidemiology, Biomarkers \& Prevention 2014 Dec;23(12):2965-2970.

(33) Kansy BA, Concha-Benavente F, Srivastava RM, Jie HB, Shayan G, Lei Y, et al. PD-1 Status in CD8(+) T Cells Associates with Survival and Anti-PD-1 Therapeutic Outcomes in Head and Neck Cancer. Cancer Res 2017 November 15;77(22):6353-6364.

(34) Cohen EEW, Cohen E, Soulières D, Le Tourneau C, Dinis J, Dinis J, et al. Pembrolizumab versus methotrexate, docetaxel, or cetuximab for recurrent or metastatic head-and-neck squamous cell carcinoma (KEYNOTE-040): a randomised, open-label, phase 3 study. The Lancet 2019 Jan 12;393(10167):156-167.

(35) Li Y, Liang L, Dai W, Cai G, Xu Y, Li X, et al. Prognostic impact of programed cell death-1 (PD-1) and PDligand 1 (PD-L1) expression in cancer cells and tumor infiltrating lymphocytes in colorectal cancer. Molecular Cancer 2016 Aug 24;15(1):55.

(36) Badoual C, Hans S, Merillon N, Van Ryswick C, Ravel P, Benhamouda N, et al. PD-1-expressing tumorinfiltrating T cells are a favorable prognostic biomarker in HPV-associated head and neck cancer. Cancer Res 2013 Jan 01;73(1):128-138.

(37) Ahn H, Yang JM, Kim H, Chung J, Ahn S, Jeong W, et al. Clinicopathologic implications of the miR-197/PD-L1 axis in oral squamous cell carcinoma. Oncotarget 2017 Sep 12;8(39):66178-66194.

(38) Straub M, Drecoll E, Pfarr N, Weichert W, Langer R, Hapfelmeier A, et al. CD274/PD-L1 gene amplification and PD-L1 protein expression are common events in squamous cell carcinoma of the oral cavity. Oncotarget 2016 Mar 15;7(11):12024-12034. 
(39) Ness N, Andersen S, Khanehkenari MR, Nordbakken CV, Valkov A, Paulsen E, et al. The prognostic role of immune checkpoint markers programmed cell death protein 1 (PD-1) and programmed death ligand 1 (PD-L1) in a large, multicenter prostate cancer cohort. Oncotarget 2017 Apr 18;8(16):26789-26801.

(40) Chintakuntlawar AV, Rumilla KM, Smith CY, Jenkins SM, Foote RL, Kasperbauer JL, et al. Expression of PD-1 and PD-L1 in Anaplastic Thyroid Cancer Patients Treated With Multimodal Therapy: Results From a Retrospective Study. Journal of Clinical Endocrinology \& Metabolism 2017 Jun 01;102(6):1943-1950.

(41) Eto S, Yoshikawa K, Nishi M, Higashijima J, Tokunaga T, Nakao T, et al. Programmed cell death protein 1 expression is an independent prognostic factor in gastric cancer after curative resection. Gastric Cancer 2016 Apr;19(2):466-471.

(42) Hsu M, Hsiao J, Chang K, Wu Y, S I, Jin Y, et al. Increase of programmed death-1-expressing intratumoral CD8 $\mathrm{T}$ cells predicts a poor prognosis for nasopharyngeal carcinoma. Modern Pathology 2010 Oct;23(10):1393-1403.

(43) Thompson RH, Dong H, Lohse CM, Leibovich BC, Blute ML, Cheville JC, et al. PD-1 is expressed by tumorinfiltrating immune cells and is associated with poor outcome for patients with renal cell carcinoma. Clinical Cancer Research 2007 Mar 15;13(6):1757-1761.

(44) Nakano O, Sato M, Naito Y, Suzuki K, Orikasa S, Aizawa M, et al. Proliferative Activity of Intratumoral CD8+ T-Lymphocytes As a Prognostic Factor in Human Renal Cell Carcinoma: Clinicopathologic Demonstration of Antitumor Immunity. Cancer Research 2001 Jul 1;61(13):5132.

(45) Sieviläinen M, Almahmoudi R, Al-Samadi A, Salo T, Pirinen M, Almangush A. The prognostic value of immune checkpoints in oral squamous cell carcinoma. Oral diseases 2018 Oct 13. 
TABLE 1.

Characteristics of the

patients.

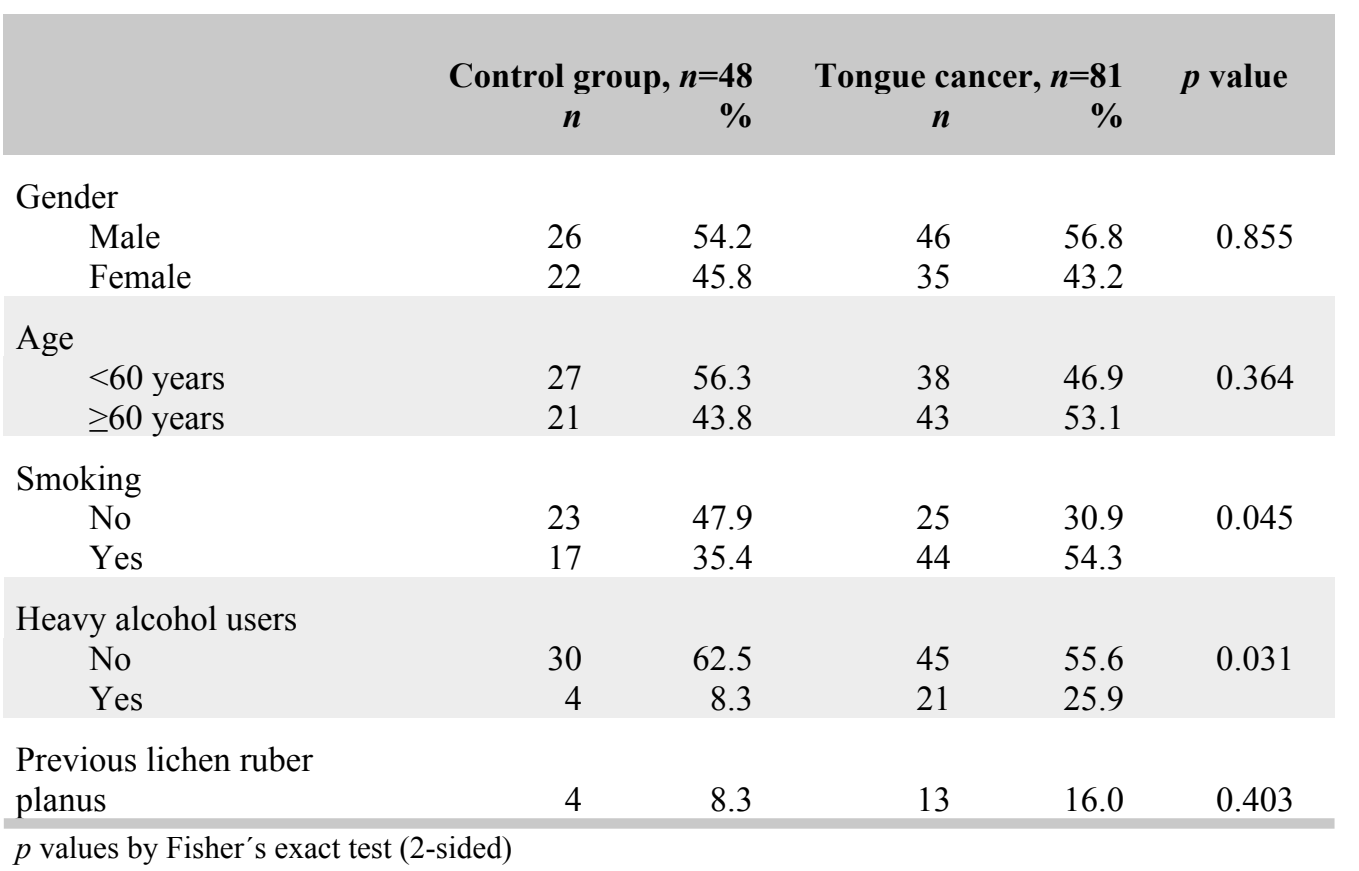

This article is protected by copyright. All rights reserved 
TABLE 2. Characteristics of the tumors.

\begin{tabular}{|c|c|c|}
\hline & Tongu & $n=81$ \\
\hline & $n$ & $\%$ \\
\hline Primary tumors & 71 & 87.7 \\
\hline Tumor location & & \\
\hline Mobile tongue & 58 & 71.6 \\
\hline Tongue basis & 20 & 24.7 \\
\hline Information not available & 3 & 3.7 \\
\hline Primary tumor size & & \\
\hline T1 & 16 & 19.8 \\
\hline $\mathrm{T} 2$ & 36 & 44.4 \\
\hline T3 & 19 & 23.5 \\
\hline $\mathrm{T} 4$ & 10 & 12.3 \\
\hline $\mathrm{cN}$ classification & & \\
\hline cN0 & 51 & 63 \\
\hline $\mathrm{cN}+$ & 30 & 37 \\
\hline $\mathrm{pN}$ classification & & \\
\hline $\mathrm{pN} 0$ & 20 & 24.7 \\
\hline pN1 & 13 & 16 \\
\hline $\mathrm{pN} 2$ & 25 & 30.9 \\
\hline $\mathrm{pNx}$ & 23 & 28.4 \\
\hline Cervical LN metastasis & & \\
\hline LN- & 37 & 45.7 \\
\hline LN+ & 44 & 54.3 \\
\hline Tumor operation & & \\
\hline Resection & 25 & 30.9 \\
\hline Resection with microvascular reconstruction & 41 & 50.6 \\
\hline Inoperable & 14 & 17.3 \\
\hline No need to operate after biopsy & 1 & 1.2 \\
\hline Cervical lymph node management & & \\
\hline No & 21 & 25.9 \\
\hline Removal of sentinel lymph nodes & 3 & 3.7 \\
\hline Functional & 55 & 67.9 \\
\hline Radical & 2 & 2.4 \\
\hline Resection margin & & \\
\hline Clear $(>=3 \mathrm{~mm})$ & 37 & 45.7 \\
\hline Close or involved $(<3 \mathrm{~mm})$ & 30 & 37 \\
\hline Unknown & 14 & 17.3 \\
\hline Tumor grade & & \\
\hline I & 29 & 35.8 \\
\hline II & 39 & 48.1 \\
\hline III & 13 & 16 \\
\hline Perineural invasion & & \\
\hline No information of PNI & 76 & 93.8 \\
\hline Yes & 4 & 4.9 \\
\hline In residive nodal metastasis & 1 & 1.2 \\
\hline Lymphatic vessel invasion & & \\
\hline No information of LVI & 77 & 95.1 \\
\hline Yes & 4 & 4.9 \\
\hline Tumor depth & & \\
\hline Low $(<4 \mathrm{~mm})$ & 9 & 11.1 \\
\hline $\operatorname{High}(>=4 \mathrm{~mm})$ & 54 & 66.7 \\
\hline Unknown & 18 & 22.2 \\
\hline Adjuvant treatment & & \\
\hline No & 27 & 33.3 \\
\hline
\end{tabular}

This article is protected by copyright. All rights reserved 


\begin{tabular}{|c|c|c|}
\hline $\begin{array}{l}\text { Chemoradiotherapy } \\
\text { Cisplatin }\end{array}$ & $\begin{array}{l}54 \\
38\end{array}$ & $\begin{array}{l}66.7 \\
46.9\end{array}$ \\
\hline \multicolumn{3}{|l|}{ Recurrence } \\
\hline No & 42 & 51.9 \\
\hline Yes & 39 & 48.1 \\
\hline \multicolumn{3}{|l|}{ Status (5 years of follow-up) } \\
\hline Alive & 43 & 53.1 \\
\hline Dead of tongue cancer & 33 & 40.7 \\
\hline Dead of other causes & 4 & 5 \\
\hline No information available the cause of death & 1 & 1.2 \\
\hline
\end{tabular}

TABLE 3. Unadjusted and adjusted Cox's regression analysis models for the variables analyzed.

\begin{tabular}{|c|c|c|c|c|c|c|c|c|}
\hline & \multicolumn{2}{|c|}{ Events } & \multicolumn{3}{|c|}{ Univariate } & \multicolumn{3}{|c|}{ Multivariable } \\
\hline & $\mathbf{N}$ & $\%$ & HR & $95 \%$ CI & $\begin{array}{c}p- \\
\text { value }\end{array}$ & HR & $95 \%$ CI & $\begin{array}{c}p- \\
\text { value }\end{array}$ \\
\hline \multicolumn{9}{|l|}{ Gender } \\
\hline Female & 13 & 44.8 & 1 & & & \multirow{2}{*}{\multicolumn{3}{|c|}{ Not entered }} \\
\hline Male & 21 & 56.8 & 1.30 & $0.65-2.59$ & 0.465 & & & \\
\hline \multicolumn{9}{|l|}{ Age } \\
\hline Under 60 years & 14 & 46.7 & 1 & & & \multirow{2}{*}{\multicolumn{3}{|c|}{ Not entered }} \\
\hline 60 years or older & 20 & 55.6 & 1.33 & $0.67-2.64$ & 0.413 & & & \\
\hline \multicolumn{9}{|l|}{ Smoking } \\
\hline No & 15 & 65.2 & 1 & & & \multirow{2}{*}{\multicolumn{3}{|c|}{ Not entered }} \\
\hline Yes & 16 & 47.1 & 1.54 & $0.76-3.13$ & 0.231 & & & \\
\hline \multicolumn{9}{|l|}{ Previous CRT or RT } \\
\hline No & 19 & 61.3 & 1 & & & \multirow{2}{*}{\multicolumn{3}{|c|}{ Not entered }} \\
\hline Yes & 2 & 66.7 & 1.10 & $0.26-4.73$ & 0.900 & & & \\
\hline \multicolumn{9}{|l|}{ Tumor size } \\
\hline$<40 \mathrm{~mm}$ & 17 & 41.5 & 1 & & & 1 & \multirow[b]{2}{*}{$0.50-3.04$} & \multirow[b]{2}{*}{0.652} \\
\hline$>=40 \mathrm{~mm}$ & 17 & 68 & 2.33 & $1.19-4.57$ & 0.014 & 1.23 & & \\
\hline \multicolumn{9}{|c|}{ Tumor invasion depth } \\
\hline Low $(<4 \mathrm{~mm})$ & 1 & 12.5 & 1 & & & \multirow{2}{*}{\multicolumn{3}{|c|}{ Not entered }} \\
\hline $\operatorname{High}(>=4 \mathrm{~mm})$ & 22 & 52.4 & 5.35 & $0.72-39.78$ & 0.101 & & & \\
\hline \multicolumn{9}{|l|}{ Resection margin } \\
\hline Clear $(>=3 \mathrm{~mm})$ & 11 & 40.7 & 1 & & & \multirow{2}{*}{\multicolumn{3}{|c|}{ Not entered }} \\
\hline Close or involved & 12 & 48 & 1.19 & $0.52-2.71$ & 0.680 & & & \\
\hline \multicolumn{9}{|c|}{ Cervical LN metastasis } \\
\hline LN- & 11 & 40.7 & 1 & & & \multirow{2}{*}{\multicolumn{3}{|c|}{ Not entered }} \\
\hline $\mathrm{LN}+$ & 23 & 59 & 1.81 & $0.88-3.73$ & 0.110 & & & \\
\hline \multicolumn{9}{|l|}{ Intratumoral PD-1+ } \\
\hline PD-1 high & 15 & 40.5 & 1 & & & 1 & & \\
\hline PD-1 $1^{\text {low }}$ & 19 & 65.5 & 1.99 & $0.01-3.93$ & 0.047 & 1.23 & $0.46-3.32$ & 0.678 \\
\hline \multicolumn{9}{|l|}{ Invasive front PD-1+ } \\
\hline PD-1 ${ }^{\text {high }}$ & 10 & 32.3 & 1 & & & 1 & & \\
\hline PD- $1^{\text {low }}$ & 13 & 68.4 & 2.99 & $1.30-6.88$ & 0.010 & 2.67 & $0.99-7.21$ & 0.052 \\
\hline
\end{tabular}


Nodal PD-1+

PD- $1^{\text {low }}$

$6 \quad 85.7$

5.7
75

1

PD-1 ${ }^{\text {high }}$

$3 \quad 75$

1.08

$0.27-4.35$

0.914

Not entered

This article is protected by copyright. All rights reserved 
FIGURE 1. The expression of programmed cell death protein 1 (PD-1) in tongue specimens based on low or high classification (see Supplement Figure 1). (A) Low PD-1 expression and no inflammation in tongue hyperplasia. (B) High PD-1 expression in tongue hyperplasia. Dotted line arrows point to low and solid line arrows point to moderate (red arrow) to strong (black arrow) staining intensity. (C) Low PD-1 expression in TSCC intratumoral area. (D) High PD-1 expression in TSCC intratumoral area. (E) Low PD-1 expression in TSCC invasive front area. (F) High PD-1 expression in TSCC invasive front area. Inflammation exists in (B, E and F). Original virtual microscope magnification 20x (in A, C-E), all others 80x.

FIGURE 3. PD-1 expression and survival curves of patients with tongue squamous cell carcinoma according to the Kaplan-Meier method.

(A) Overall survival (OS) for PD-1+ staining in all TSCC patients. (B) Disease-specific survival (DSS) for PD-1+ staining in all TSCC patients. (C) OS for PD- $1+$ staining in patients with greater tumor size ( $\geq 40 \mathrm{~mm}$ ). (D) DSS for PD-1+ staining in patients with tumor size $\geq 40 \mathrm{~mm}$. (E) OS for PD-1+ staining in patients with cervical lymph node metastasis LN+. (F) DSS for PD-1+ staining in patients with cervical lymph node metastasis LN+. (G) OS for PD-1+ staining in patients with greater tumor invasion depth $(\geq 4 \mathrm{~mm})$. (H) DSS for PD- $1+$ staining in patients with tumor invasion depth $\geq 4 \mathrm{~mm}$. (I) OS for PD-1+ staining in patients with narrow or involved positive resection margin $(<3 \mathrm{~mm}$ ). (J) DSS for PD-1+ staining in patients with resection margin $<3 \mathrm{~mm}$. P-values by Log-rank test. 
A

C
B

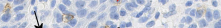
$\rightarrow \rightarrow 090$

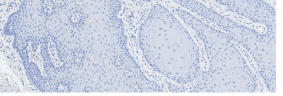

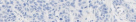

\section{$20+5$}
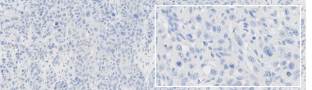

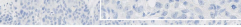

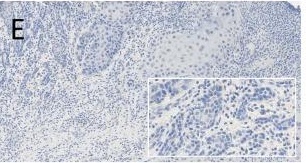

D
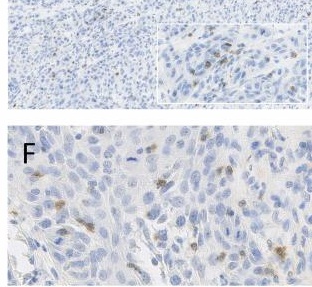

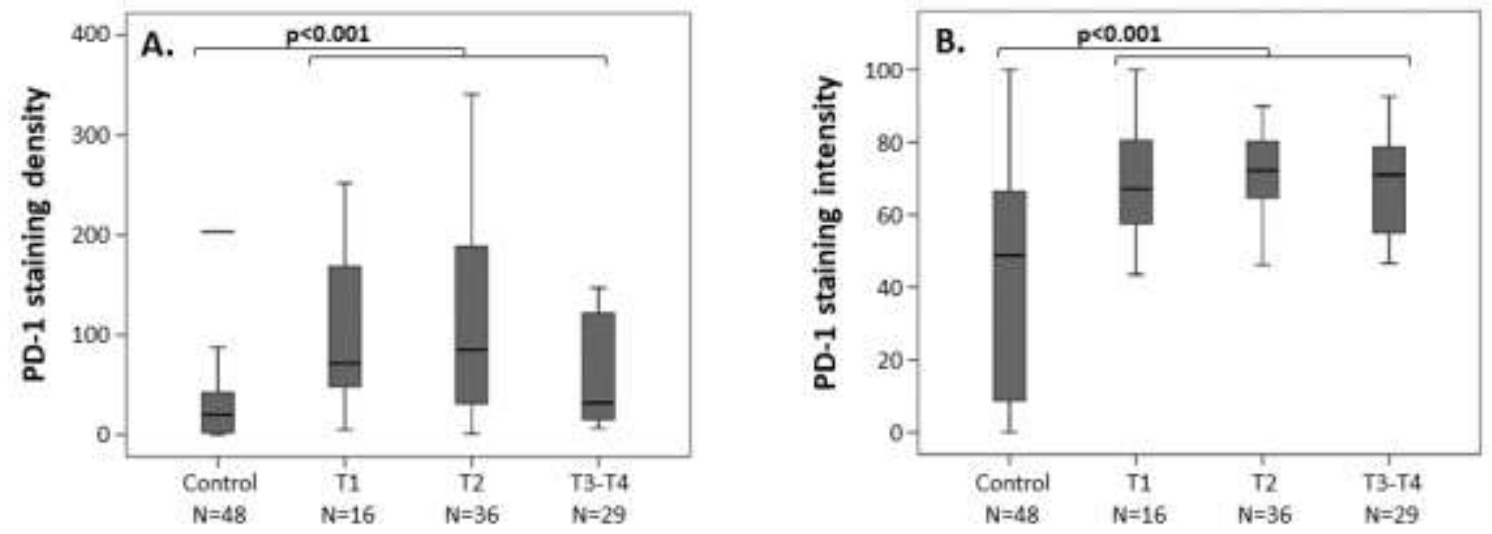

FIGURE 2. Comparison of programmed cell death protein 1 (PD-1) expression in benign tongue tissue and the intratumoral tongue squamous cell carcinoma tissue. (A) Y-axis indicates PD-1 positively stained cells number /mm2 in benign tongue and in tongue squamous cell carcinoma. (B) Y-axis indicates the percentage of high intensity stained cells from all PD-1 positively stained cells in benign tongue and in tongue squamous cell carcinoma. 

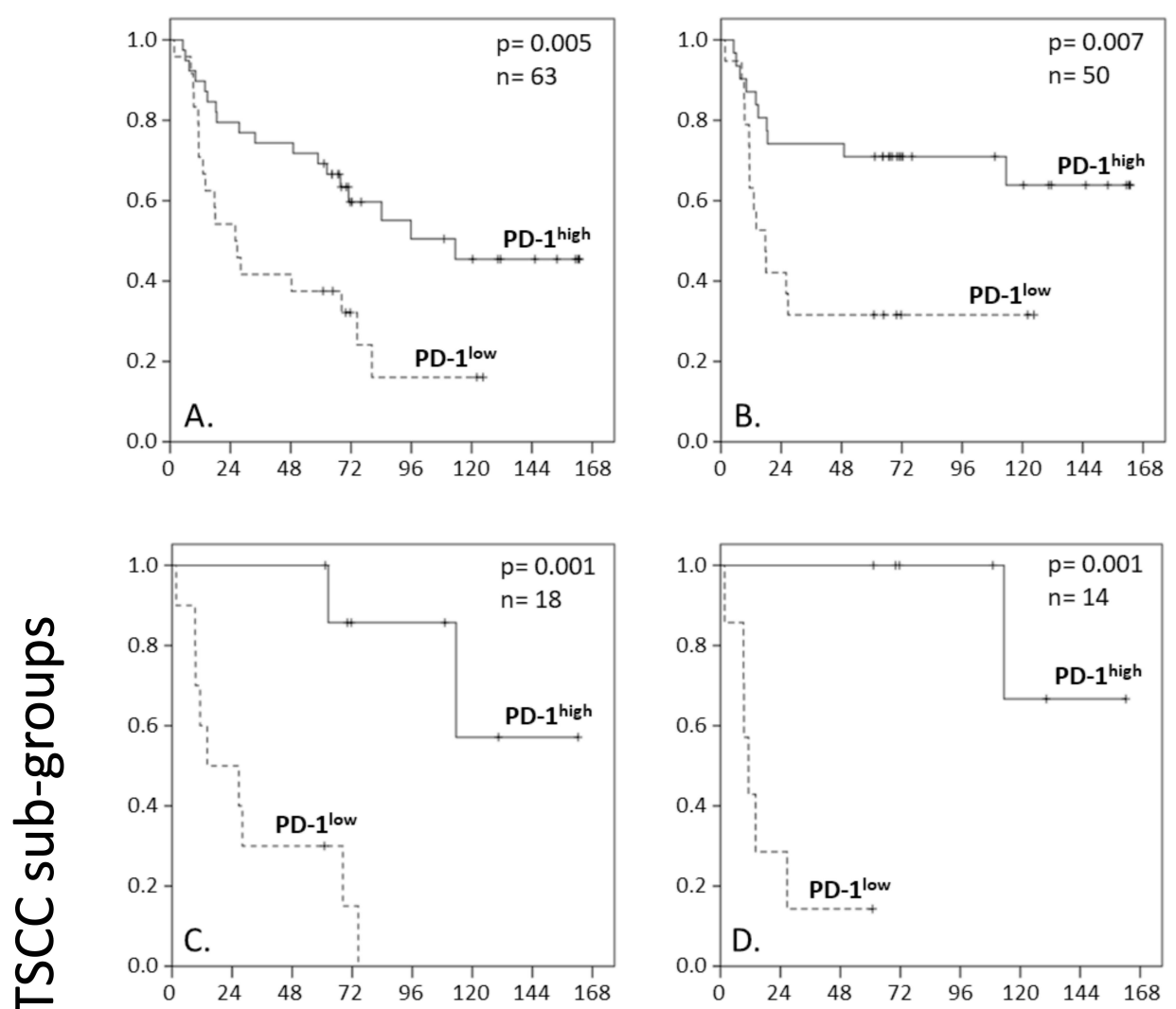

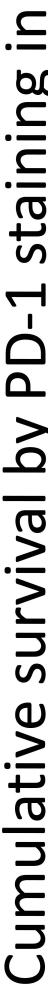
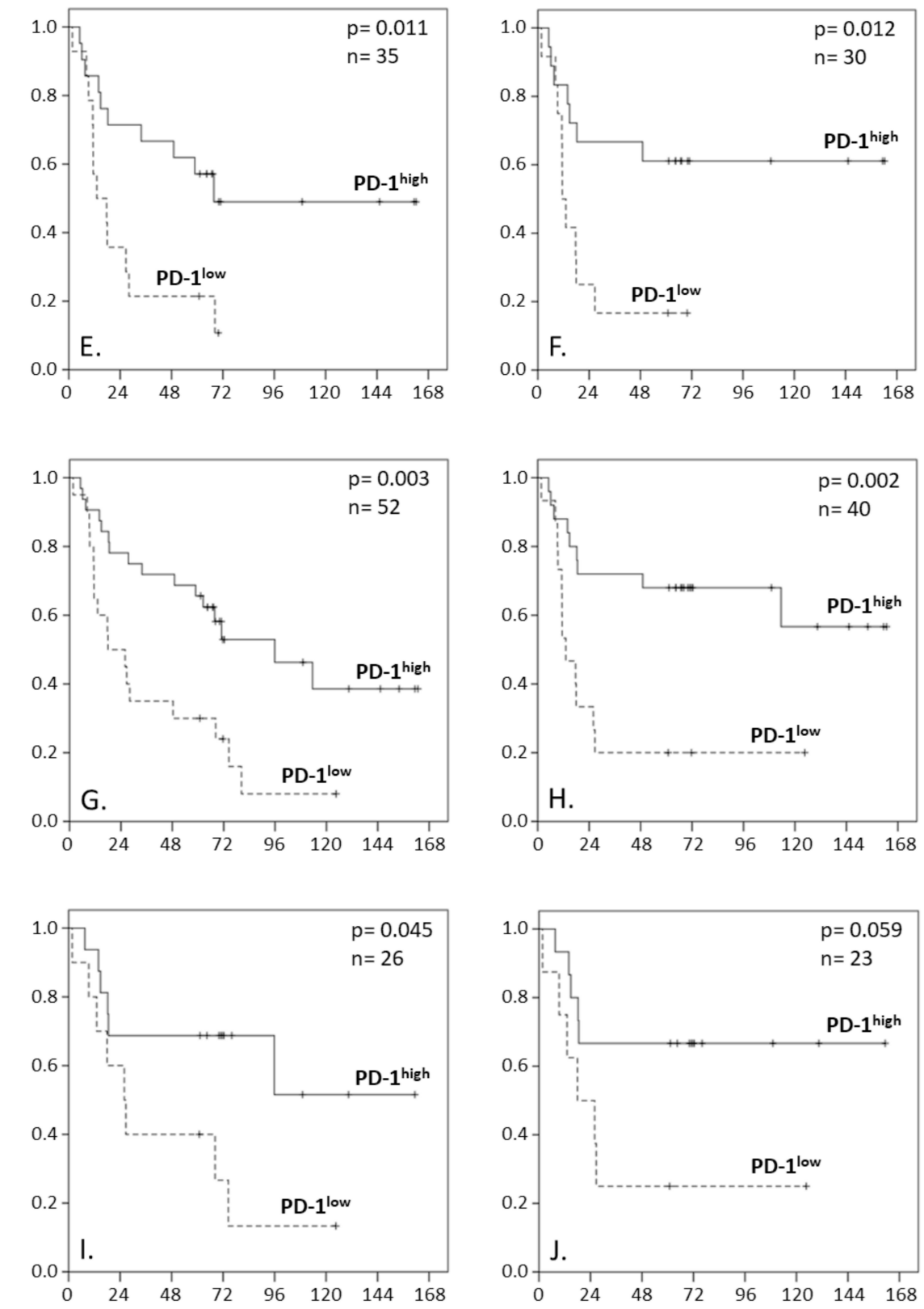

Follow-up time in months 